\begin{tabular}{|c|c|}
\hline Title & Print-specific N170 involves multiple subcomponents for Japanese Hiragana \\
\hline Author(s) & Uno, Tomoki; Okumura, Y asuko; Kasai, Tetsuko \\
\hline Citation & $\begin{array}{l}\text { Neuroscience letters, } 650,77-81 \\
\text { https:/doi.org/10.1016/.neulet.2017.04.020 }\end{array}$ \\
\hline Issue Date & 2017-05-22 \\
\hline Doc URL & http:/hdl.handle.net/2115/73709 \\
\hline Rights & $\begin{array}{l}\text { (9 2017. This manuscript version is made available under the CC-BY-NC-ND } 4.0 \text { license } \\
\text { http://reativecommons.org/icenses/by-nc-nd/4.0/ }\end{array}$ \\
\hline Rights(URL) & http://creativecommons.org/icenses/by-nc-nd/4.0/ \\
\hline Type & article (author version) \\
\hline File Information & uno_NSL_sumbit_rev2.pdf \\
\hline
\end{tabular}

Instructions for use 


\title{
Print-specific N170 involves multiple subcomponents for Japanese Hiragana
}

\author{
Tomoki Uno ${ }^{\text {a }}$, Yasuko Okumura ${ }^{\mathrm{b}}$, and Tetsuko Kasai ${ }^{\mathrm{c}}$
}

${ }^{a}$ Graduate School of Education, Hokkaido University, Nishi-7, Kita-11, Kita-ku, Sapporo, Hokkaido, Japan.

${ }^{\mathrm{b}}$ Department of Developmental Disorders, National Institute of Mental Health, National Center of Neurology and Psychiatry, 4-1-1, Ogawahigashi-cho, Kodaira, Tokyo, Japan.

E-mail: y.okumura@ncnp.go.jp

${ }^{\mathrm{c}}$ Faculty of Education, Hokkaido University, Nishi-7, Kita-11, Kita-ku, Sapporo, Hokkaido, Japan.

E-mail: tetsu@edu.hokudai.ac.jp

Correspondence to:

Tomoki Uno

Graduate School of Education, Hokkaido University

Nishi-7, Kita-11, Kita-ku, Sapporo, Hokkaido, Japan

Tel \& Fax: +81-11-706-3113

E-mail: tuno_1701@eis.hokudai.ac.jp 


\begin{abstract}
Print-specific N170 in event-related potentials is generally considered to reflect relatively automatic processing for letter strings, which is crucial for fluent reading. However, our previous studies demonstrated that print-specific N170 for transparent Japanese Hiragana script consists of at least two subcomponents under rapid stimulus presentation: an attention-related left-lateralized N170 and a bilateral N170 associated with more automatic orthographic processes (Okumura, Kasai \& Murohashi, 2014, 2015). The present study aimed to confirm the latter component by controlling presentation frequency of letters and nonlinguistic visual controls (i.e., symbols), but found a quite different pattern of results; an enhanced occipito-temporal positivity for words (80-120 ms poststimulus) followed by the typical left-lateralized N170 and an enhanced parietal negativity for nonwords (150-200 ms). These results should provide further insights into the interaction processes between attention and early stages of print processing.
\end{abstract}

Keywords: Visual word processing; Event-related potential; N170; Attention 


\section{Introduction}

Fluent and rapid reading requires highly efficient decoding of visually presented words, processing of which involves multiple and complex processes that initiate and operate in coordination without the reader's attention [1]. Consistently, previous studies have demonstrated that visual words can be processed automatically, as evidenced by the famous Stroop effect [2] and masked priming effects [3-5]. On the other hand, these effects can also be modulated by attention toward print stimuli so that the visual word processing may not be completely automatic $[6,7]$. Revealing the degree of automaticity and the involvement of attention in print processing is important for understanding the mechanisms of normal as well as impaired reading, and considering clinical applications for reading difficulties.

Event-related potentials (ERPs) with a high temporal resolution of brain activities are useful indices for early processing stages, which involve both perception and attention [e.g., 8]. In expert readers, letter strings, including words, pseudowords and nonwords, elicited a negative ERP enhancement at 140-200 ms after the stimulus onset over the left occipito-temporal scalp region, in comparison to control stimuli such as

symbols and figures (English: [9], French: [10, 11], Chinese: [12], Japanese: [13]). This effect is named print-specific N170, and its neural source has been localized at a portion of the left fusiform gyrus, which is known as the visual word form area [14]. The printspecific N170 is generally considered to reflect the orthographic processing [15-17], while the left-lateralization may also involve implicit phonological processing or 
spelling-to-sound conversion, based on the fact that pseudowords with a transparent orthography (i.e., German) elicited left-lateralized N170 but those with an opaque orthography (i.e., English) elicited bilateral N170 [9, 18].

The left-lateralized N170 is generally considered to reflect automatic print processing since it can be observed similarly under linguistic [11] and non-linguistic tasks $[10,19]$. However, in our previous studies, we found bilateral N170 enhancement for letter strings (words and nonwords) when the participants attended to the color of a fixation cross [20] but left-lateralized N170 when the color of strings was attended [21], despite the use of extremely transparent script (i.e., Hiragana that has almost one-to-one corresponds between letters and syllables/mora). These results indicate that printspecific N170 involves two subcomponents: the bilateral N170 associated with relatively automatic print processing, and the left-lateralized N170 associated with attention-related phonological mapping [22]. We may have found such an attention effect likely because our rapid presentation condition (2-3 strings per second) restricted the amount of attention available for letter-strings, which may have been ceiling in the previous studies with the typical, or much slower, presentation rates (one stimuli per several seconds).

In the present study, we aimed to confirm the finding of Okumura et al. [20] and used an experimental design and procedure that were identical to them, except that each block consisted of two, instead of three, types of stimuli presented at equal frequencies (i.e., word-symbol, nonword-symbol and word-nonword blocks were conducted in a 
counterbalanced order). In Okumura et al. [20], Hiragana words, nonwords and symbol strings were randomly mixed within each experimental block through the whole experiment, which caused an imbalanced presentation frequency of letter versus nonletter stimuli (2:1). Although they have shown print-specific N170 under a condition that minimized attention, the imbalanced presentation frequency may have weighted print processing, since it can be biased by the property of stimuli that predominate an experimental block [23-25]. Therefore, eliminating such weight by the above manipulation should further clarify the automaticity of print-specific processes suggested from our previous study [20]. However, the present study found an unexpected, novel pattern of print-specific N170, which may cast new light on interaction processes between print processing and attention.

\section{Material and Methods}

\section{Participants}

Twelve native Japanese speakers participated in this experiment ( 5 females, 20-23 years). All participants were right-handed and had normal or corrected-to-normal vision. They all gave their written informed consent according to the Declaration of Helsinki. Data from one participant were excluded from the analysis due to excessive artifacts.

\section{Stimuli and Procedure}

Stimuli consisted of 100 Hiragana words, nonwords and alphanumeric symbol strings (Table 1). All stimuli consisted of four letters or symbols. Each stimulus was presented for $100 \mathrm{~ms}$ with a random interstimulus interval of 300-600 ms (50 ms/step). 
The participants fixated on a central fixation cross during the experimental blocks and were required to press a button with the right thumb as quickly as possible when the fixation cross occasionally turned from light gray to blue (i.e., a target). For further details of stimuli and procedure, see [20].

As an important modification in the procedure, in each block, two of the three types of stimuli (100 stimuli each) and 20 targets were presented in random order, which gave three types of block: word-symbol, nonword-symbol, and word-nonword blocks. Each type of block was presented twice in a row, so that there were six blocks in total. The order of the block types was counterbalanced across the participants. Stimulus presentation and response collection were controlled by E-prime software (version 2.0; Psychology Software Tools, Sharpsburg, PA, USA). At the beginning of the experiment, the participants performed a short practice block.

\section{Recordings and Analysis}

Behavioral performance, including the percentage of correct target detections (hits) and reaction times (RTs) for hits, was measured. Responses that occurred within 150$800 \mathrm{~ms}$ after target presentation were scored as correct, and responses to other stimuli were classified as false alarms (FAs). The behavioral measures were subjected to a oneway repeated measures analysis of variance (ANOVA) including block type (wordsymbol/nonword-symbol/word-nonword).

An electroencephalogram (EEG) was recorded using an electrode cap (Easycap $\mathrm{GmbH}$, Herrsching, Germany) with $28 \mathrm{Ag} / \mathrm{AgCl}$ electrodes aligned according to the 
extended International 10-20 System (F7/8, F3/4, Fz, T7/8, C3/4, Cz, TP7/8, CP3/4, $\mathrm{CPz}, \mathrm{P} 7 / 8, \mathrm{P} 3 / 4, \mathrm{Pz}, \mathrm{PO} 7 / 8, \mathrm{PO} 3 / 4, \mathrm{POz}, \mathrm{O} 1 / 2$, and $\mathrm{Oz}$ ). All channels were referenced to the nose tip. The electrooculogram (EOG) was recorded bipolarly through electrodes placed at Fp1 and below the left eye (vertical) and at the outer canthi of both eyes (horizontal). The EEGs and EOGs were amplified using a SynAmps amplifier (NeuroScan, Sterling, VA, USA), filtered with a band-pass of $0.1-30 \mathrm{~Hz}$, and sampled at $500 \mathrm{~Hz}$. Electrode impedance was maintained below $10 \mathrm{k} \Omega$.

The continuous EEG signals were divided into epochs from $200 \mathrm{~ms}$ before to 800 ms after stimulus onset and were baseline-corrected relative to the $200 \mathrm{~ms}$ prestimulus interval. Epochs with artifacts above $75 \mu \mathrm{V}$ at any EEG or EOG channel and those immediately after the target were excluded before averaging. The minimum and maximum numbers of epochs averaged for words (with nonwords: 78-180, $M=149$; with symbols: $100-180, M=151$ ), nonwords (with words: $70-182, M=148$; with symbols: 95-173 ( $M=149$ ), and symbols (with words: 99-173, $M=150$; with nonwords: 90-186, $M=146)$ were comparable.

\section{Results}

\section{Behavioral data}

Target detection was sufficiently accurate (word-symbol: $M=96.5 \%, S D=1.2 \%$; nonword-symbol: $M=95.2 \%, S D=1.8 \%$; word-nonword: $M=96.4 \%, S D=1.1 \%$ ) and quick (word-symbol: $M=348 \mathrm{~ms}, S D=9 \mathrm{~ms}$; nonword-symbol: $M=355 \mathrm{~ms}, S D=10 \mathrm{~ms}$; word-nonword: $M=354 \mathrm{~ms}, S D=11 \mathrm{~ms}$ ) in all block types. There was no significant 
effect of block type for hit rate $(F(2,20)=0.26, p>.6)$, RTs $(F(2,20)=0.38, p>.6)$, or FA rate $(F(2,20)=1.19, p>.3)$

\section{ERP data}

As shown in Figure 1, the earliest difference among stimuli was observed as a positive enhancement for words with a peak at approximately $100 \mathrm{~ms}$ post-stimulus over occipito-temporal sites (P7/8). According to the purpose of this study, analyses focused on early ERPs at posterior electrode sites that showed sensitivity to the stimulus types. Based on a visual inspection of grand-average ERPs, 80-120 ms at occipitotemporal sites (P7/8) and 150-200 ms at $\mathrm{P} 7 / 8$ and $\mathrm{P} 3 / 4$ were chosen as the intervals for computing mean amplitudes (Figure 1).

As preliminary analyses for these intervals and electrode sites (Figure 2), the effects of paired stimuli were examined separately for the three stimulus types via two-way repeated measures ANOVA involving the factor of hemisphere (left, right) and other stimuli in a given block (i.e., nonwords/symbols for words; words/symbols for nonwords; words/nonwords for symbols). As a result, the effects of paired stimuli for letter strings were insignificant for all intervals and electrode sites of interest (all $p s>.1$, Table 2).

Therefore, we collapsed the different blocks and conducted two-way repeated measures ANOVA including the factor of hemisphere and stimulus type (word, nonword, symbol). The Greenhouse-Geisser correction was applied to contrasts with more than 1 degree of freedom and pairwise comparisons were conducted with the 
Bonferroni-correction, as with behavioral measures. For the mean amplitudes during $80-120 \mathrm{~ms}$ (Figure 3a), there was a main effect of stimulus type $(F(2,20)=3.69$, $p<.05)$. A pairwise comparison showed that words elicited greater positivity than nonwords $(p<.05)$ and symbols $(p<.02)$, whereas there was no difference between nonwords and symbols $(p>.7)$.

In the 150-200 ms interval, all stimuli elicited negative ERPs that were maximal at around $180 \mathrm{~ms}$ at the occipito-temporal region, and these were more negative for print stimuli (i.e., words and nonwords) than for symbols (Figure 1). A main effect of stimulus type was significant $(F(2,20)=11.35, p<.01)$, and a pairwise comparison revealed that this negativity was greater for nonwords than for symbols $(p<.01)$. More importantly, there was also a two-way interaction between hemisphere and stimuli $(F$ $(2,20)=4.8, p<.05)$. In post-hoc tests, a simple main effect of stimulus type was significant only at the left electrode site $(F(2,20)=19.83, p<.01)$, and the negativities for words and nonwords were greater than that for symbols (word vs. symbol: $p<.02$, nonword vs. symbol: $p<.01)$.

In the same 150-200 ms interval at parietal sites (P3/P4), however, clear negative enhancement was observed for nonwords compared to words and symbols (Figure 3b), which was supported by a significant main effect of stimulus type $(F(2,20)=12.7$, $p<.01)$. Pairwise comparisons showed that the negativity for nonwords was significantly greater than those for the other stimulus types (nonword vs. word: $p<.03$, nonword vs. symbol: $p<.01$ ), while the difference between ERPs for words and symbols was not 
significant $(p>.1)$

\section{Discussion}

The present study aimed to clarify the functional significance of subcomponents of letter-specific N170 for Japanese Hiragana when attention is restricted. We controlled presentation frequency of letters within a block, when stimuli were rapidly presented and task-irrelevant in a similar way to Okumura et al. [20], and found several unexpected patterns of results.

As an earliest effect, we found an enhancement of occipito-temporal positivity for words (80-120 ms poststimulus) compared with nonword and symbol. This effect should be associated with acquired lexical representation, rather than differences in lowlevel visual features, since the constituents of the words and nonwords were physically identical [see 20,21]. The result is striking because early lexical effects have been found only when letter strings were task-relevant (P1 under lexical decision tasks [2628]; C1 under the color discrimination of letter/symbol strings [21]). These suggest that attention was allocated toward strings somewhat in the present study.

It is well known that attention amplifies or suppresses early sensory processing (i.e., "gain control" [29]), which is often reflected as P1 amplitude modulation due to spatial attention [30]. Although the present study did not manipulate spatial attention, the P1 lexical effect may suggest that the gain control mechanism especially operates on early neural activities associated with perceptual processing for familiar or well-learned words. On the other hand, the absence of such an effect in most studies [9-13] might 
reflect the suppression of early word-related activities due to phonological and/or semantic task demands. These considerations imply that early word processing in the visual cortex depends on attention, task demand, or the interaction between them, which requires further clarifications.

During the 150-200 ms interval, the present study found the typical left-lateralized N170 [9-13], in contrast to the bilateral N170 observed in Okumura et al. [20]. This inconsistency also suggests that greater attention was allocated to letter/symbol strings in the present study, because the left-lateralization effect has been found when stimuli themselves were attended [21]. Such an attentional allocation toward task-irrelevant stimuli is not due to adaptation or priming across letter strings according to the results of preliminary analyses regarding paired stimuli within blocks. As a speculation, presenting three types of blocks with different stimulus combination may have retained higher level of attention during the current experiment, and facilitated orthographic and/or phonological processes that the typical N170 left-lateralization effect reflects $[15-17,22]$. However, occasional individual differences or other unspecified factors may also be involved.

The most prominent finding in the present study was the enhancement of parietal negativity for nonwords (150-200 ms). To the best of our knowledge, the parietal N170 has not been reported previously. Although the P1 and left-lateralized N170 in the present study suggest that somewhat attention was deployed to task-irrelevant stimuli, such a nonword-specific response was not observed when attention was explicitly 
directed to letter strings $[9,10,17,21]$. Thus, attention involuntarily allocated to letters, rather than task-related attention, may elicit the parietal N170 for nonwords.

In several neuroimaging studies, the posterior parietal cortex (PPC) is shown to be involved in letter processing. Words with wide interletter spacing induced a length effect (i.e., reading latency increases as the number of letters, reflecting letter-by-letter processing) and increased activation in the bilateral PPC [31]. Moreover, right PPC activity (100-300 ms) in response to words with an unfamiliar appearance was found in magnetoencephalography [32]. Since the PPC is involved in visual attention [33], these findings may suggest a link between letter-by-letter processing and attention.

The parietal N170 observed in the present study may also involve letter-by-letter processing. More specifically, since it tended to be larger in the left hemisphere (i.e., statistically insignificant), it might reflect grapheme-phoneme mapping, or letter-byletter phonological processing in Hiragana, which has no ambiguity in letter-sound correspondences. The functional significance of the parietal N170 and its relationship with the PPC activities should be further considered in future studies.

\section{Conclusions}

The present study, together with our previous studies [20,21], suggested three subcomponents of print-specific N170: bilateral N170, left-lateralized N170, and parietal N170, which may be associated with relatively automatic orthographical processing, grapheme-phoneme mapping, and letter-by-letter processing, respectively. These ERPs may cast new light on the interaction processes of visual word processing 
and attention. Further studies are necessary to clarify whether or not these early multiple processes of print processing are limited to transparent Hiragana strings. 


\section{References}

[1] D. LaBerge, S.J. Samuels, Toward a theory of automatic information processing in reading, Cogn. Psychol. 6 (1974) 293-323.

[2] C.M. MacLeod, Half a century of Research on the Stroop Effect: An integrative review, Psychol. Bull. 109 (1991) 163-203.

[3] K.I. Forster, C. Davis, C. Schoknecht, R. Carter, Masked priming with graphemically related forms: Repetition or partial activation? Q. J. Exp. Psychol. A. 39 (1987) 211-251.

[4] G.W. Humphreys, L.J. Evett, D.E. Taylor, Automatic phonological priming in visual word recognition, Mem. Cognit. 10 (1982) 128-152.

[5] J.H. Neely, Semantic priming and retrieval from lexical memory: Roles of inhibitionless spreading activation and limited-capacity attention, J. Exp. Psychol. Gen. 106 (1977) 226-254.

[6] D. Besner, J.A. Stoltz, C. Boutilier, The Stroop effect and the myth of automaticity, Psychon. Bull. Rev. 4 (1997) 221-225.

[7] J. Lachter, K.I. Forster, E. Ruthruff, Forty-five years after Broadbent (1985): Still no identification without attention, Psychol. Rev. 111 (2004) 880-913.

[8] S.J. Luck, G. F. Woodman, E.K. Vogel, Event-related potential studies of attention, Trends Cogn Sci. 4 (2000) 432-440.

[9] U. Maurer, D. Brandeis, B.D. McCandliss, Fast, visual specialization for reading in English revealed by the topography of the N170 ERP response, Behav. Brain Funct. 1 
(2005) 13.

[10] S. Bentin, Y. Mouchetant-Rostaing, M.H. Giard, J.F. Echallier, J. Pernier, ERP manifestations of processing printed words at different psycholinguistic levels: time course and scalp distribution, J. Cogn. Neurosci. 11 (1999) 235-260.

[11] G. Simon, C. Bernard, P. Largy, R. Lalonde, M. Rebaï, Chronometry of visual word recognition during passive and lexical decision tasks: An ERP investigation, Int. J. Neurosci. 114 (2004) 1401-1432.

[12] S. E. Lin, H. C. Chen, J. Zhao, S. Li, S. He, X. C. Weng, Left-lateralized N170 response to unpronounceable pseudo but not false Chinese characters-the key role of orthography, Neuroscience 190 (2011) 200-206.

[13] U. Maurer, J.D. Zevin, B.D. McCandliss, Left-lateralized N170 effects of visual expertise in reading: evidence from Japanese syllabic and logographic scripts, J. Cogn. Neurosci. 20 (2008) 1878-1891.

[14] B. D. McCandliss, L. Cohen, S. Dehaene, The visual word form area: expertise for reading in the fusiform gyrus, Trends Cogn. Sci. 7 (2003) 293-299.

[15] A. M. Proverbio, L. Vecchi, A. Zani, From orthography to phonetics: ERP measures of grapheme-to-phoneme conversion mechanisms in reading, J. Cogn. Neurosci. 16 (2004) 301-317.

[16] A.M. Proverbio, F. Wiedemann, R. Adorni, V. Rossi, M. Del Zotto, A. Zani, Dissociating object familiarity from linguistic properties in mirror word reading, Behav. Brain Funct. 3 (2007) 43. 
[17] G. Simon, L. Petit, C. Bernard, M. Rebaï, N170 ERPs could represent a logographic processing strategy in visual word recognition, Behav. Brain Funct. 3 (2007) 21.

[18] U. Maurer, S. Brem, K. Bucher, D. Brandeis, Emerging neurophysiological specialization for letter strings, J. Cogn. Neurosci. 17 (2005) 1532-1552.

[19] A. C. N. Wong, I. Gauthier, B. Woroch, C. DeBuse, T. Curran, An early electrophysiological response associated with expertise in letter perception, Cogn. Affect. Behav. Neurosci. 5 (2005) 306-318.

[20] Y. Okumura, T. Kasai, H. Murohashi, Early print-tuned response with minimal involvement of linguistic processing in Japanese Hiragana strings, NeuroReport. 25 (2014) 410-414.

[21] Y. Okumura, T. Kasai, H. Murohashi, Attention that covers letters is necessary for the left-lateralization of an early print-tuned ERP in Japanese hiragana, Neuropsychologia. 69 (2015) 22-30.

[22] U. Maurer, B.D. McCandliss, The development of visual expertise for words: The contribution of electrophysiology, in: E.L. Grigorenko, A.J. Naples (Eds.), Single-Word Reading: Cognitive, Behavioral and Biological Perspectives, Mahwah, NJ: Lawrence Erlbaum Associates, 2007, pp. 43-64.

[23] B. Baluch, D. Besner, Visual word recognition: Evidence for strategic control of lexical and nonlexical routines in oral reading, J. Exp. Psychol. Learn. 17 (1991) 664652. 
[24] G. B. Simpson, H. Kang, The flexible use of phonological information in word recognition in Korean, J. Mem. Lang. 33 (1994) 319-331.

[25] J.D. Zevin, A.B. Balota, Priming and attentional control of lexical and sublexical pathways during naming, J. Exp. Psychol. Learn. Mem. Cogn. 26 (2000) 121-135. [26] O. Hauk, H.M. Davis, M. Ford, F. Paulvermuller, W.D. Marslen-Wilson, The time course of visual word recognition as revealed by linear regression analysis of ERP data, NeuroImage. 30 (2006) 1383-1400.

[27] S.J. Segalowitz, X. Zheng, An ERP study of category priming: Evidence of early lexical semantic access, Biol. Psychol. 80 (2009) 122-129.

[28] S.C. Sereno, K. Rayner, M.I. Posner, Establishing a time-line of word recognition: evidence from eye movements and event-related potentials, NeuroReport. 9 (1998) $2195-2200$.

[29] S.A. Hillyard, E.K. Vogel, S.J. Luck, Sensory gain control (amplification) as a mechanism of selective attention: electrophysiological and neuroimaging evidence, Philos. Trans. R. Soc. Lond. B. Biol. Sci. 353 (1998) 1257-1270.

[30] H.J. Heinze, S.J. Luck, G.R. Mangun, S.A. Hillyard, Visual event-related potentials index focused attention within bilateral stimulus arrays. I. Evidence for early selection. Electroencephalogr Clin Neurophysiol. 75 (1990) 511-527.

[31] L. Cohen, S. Dehaene, F. Vinckier, A. Jobert, A. Montavont, Reading normal and degraded words: contribution of the dorsal and ventral pathways, NeuroImage. 40 (2008) 353-366. 
[32] K. Pammer, P. Hansen, I. Holliday, P. Cornelissen, Attentional shifting and the role of the dorsal pathway in visual word recognition, Neuropsychologia. 44 (2006) 29262936.

[33] M. Corbetta, G.L. Shulman, Human cortical mechanisms of attention during visual orienting and search, Philos. Trans. R. Soc. Lond. B. Biol. Sci. 353 (1998) 1353-1362. 


\section{Figure Captions}

Figure 1. (a) Grand-average ERPs for nontarget stimulus at occpito-temporal (P7, P8) and parietal (P3, P4) sites. Red and gray bands indicate the intervals of mean amplitude during the $80-120 \mathrm{~ms}$ and 150-200 ms after stimulus onset, respectively. (b) Equipotential maps for each type of stimuli during these latency ranges.

Figure 2. Grand-average ERPs for words (top), nonwords (middle), and symbols (bottom) with respect to each stimulus combination. Red and gray bands indicate the intervals of mean amplitude during the 80-120 ms and 150-200 ms after stimulus onset, respectively.

Figure 3. The mean amplitudes during the (a) 80-120 ms and (b) 150-200 ms intervals after stimulus presentation. Error bars indicate the standard errors of the mean. 
Table 1. Examples and properties of each stimulus type.

\begin{tabular}{|c|c|c|c|}
\hline Type & Example & Pronunciation & Meaning (in English) \\
\hline \multirow{3}{*}{ Word } & あいさつ & /a-i-sa-tsu// & Greetings \\
\hline & & & \\
\hline & おんがく & /o-n-ga-kw/ & Music \\
\hline \multirow{3}{*}{ Nonword } & あいたる & /a-i-ta-ru// & - \\
\hline & & & \\
\hline & みりがき & /mi-ri-ga-ki/ & - \\
\hline \multirow{3}{*}{ Symbol } & \#\$\&@ & - & - \\
\hline & & & \\
\hline & $\%=? \$$ & - & - \\
\hline
\end{tabular}


Table 2 . The $P$ values regarding the effect of paired stimuli.

Note: *indicates interaction with hemisphere. $d . f .=1,10$

\begin{tabular}{lcccc}
\hline \hline & & Word & Nonword & Symbol \\
\cline { 3 - 5 } latency range & electrode sites & with symbols & with words & with words \\
& & vs. with nonwords & vs. with symbols & vs. with nonwords \\
\hline \multirow{2}{*}{$80-120 \mathrm{~ms}$} & occipito-temporal & .26 & .25 & .96 \\
\hline \multirow{2}{*}{$150-200 \mathrm{~ms}$} & occipito-temporal & .44 & .84 & .22 \\
& parietal & .19 & .64 & $.047^{*}$ \\
\hline \hline
\end{tabular}


(a)
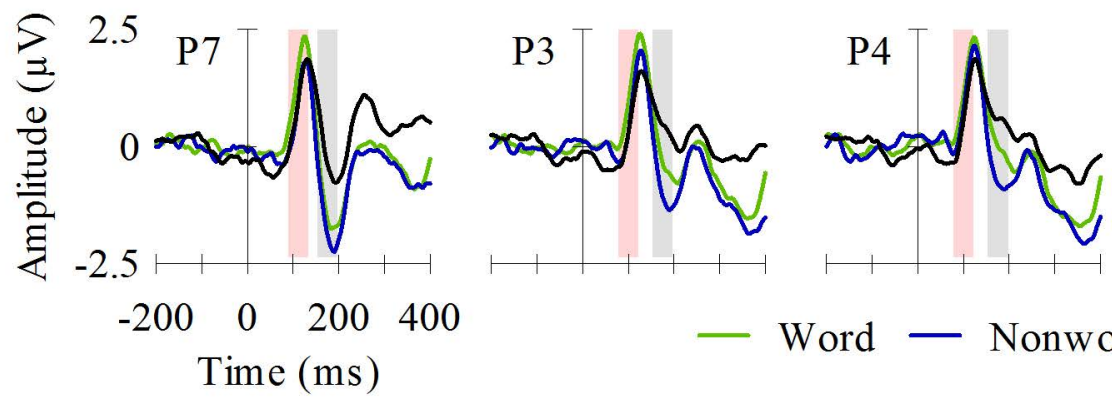

Figure 1

(b)

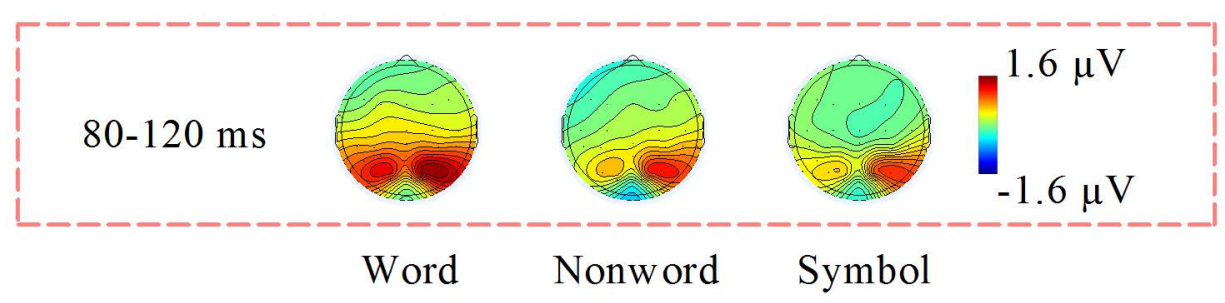

$150-200 \mathrm{~ms}$
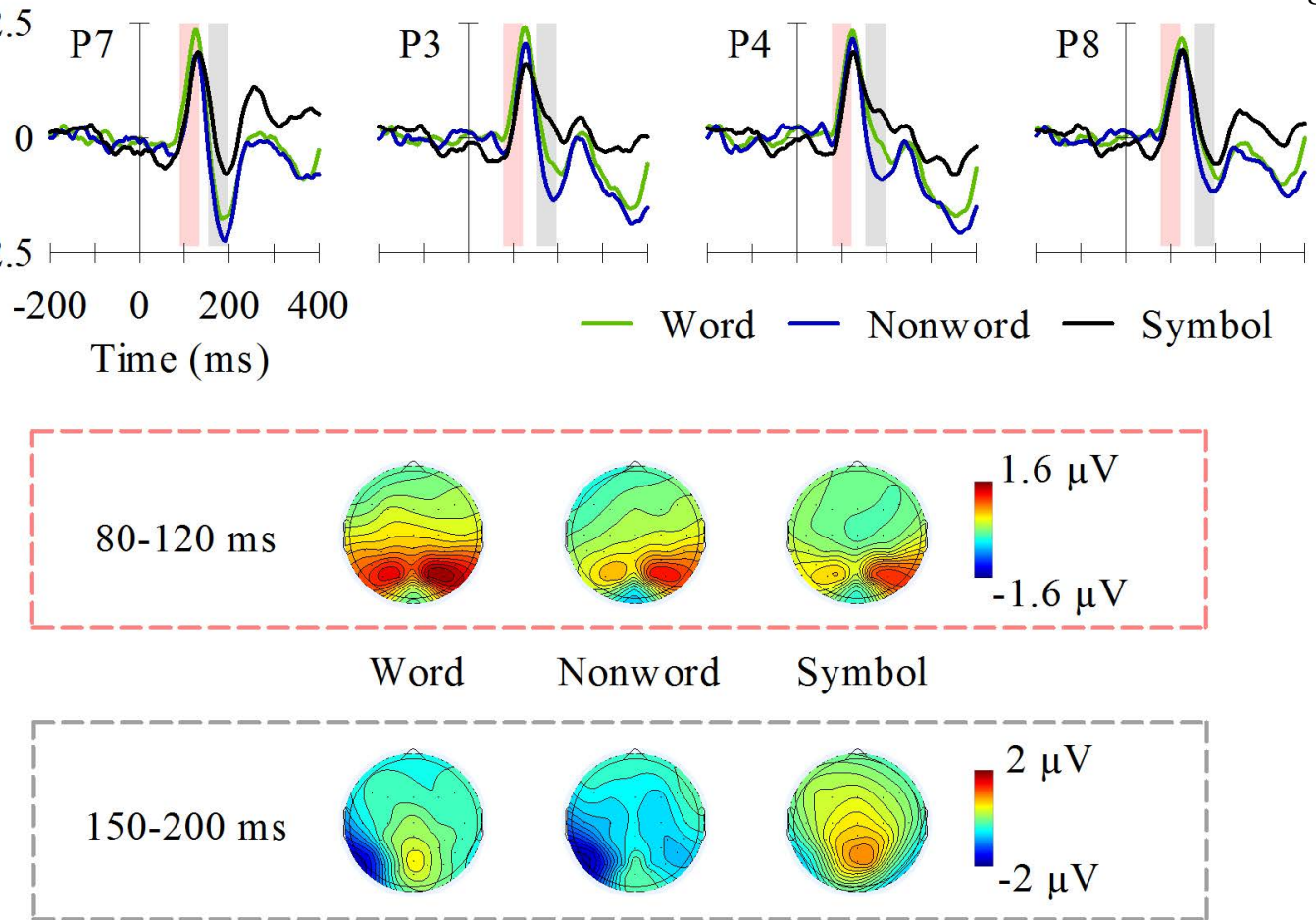
Figure 2

Words

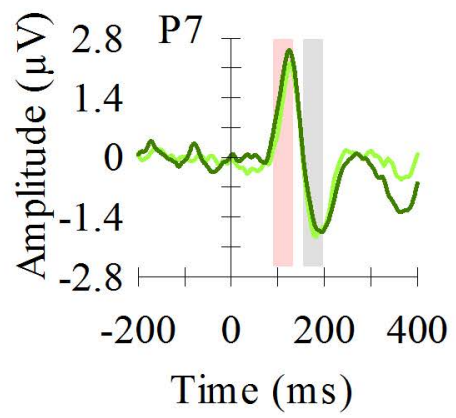

Nonw ords

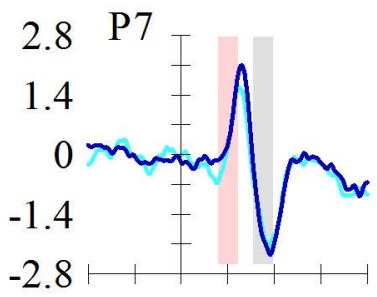

Symbols

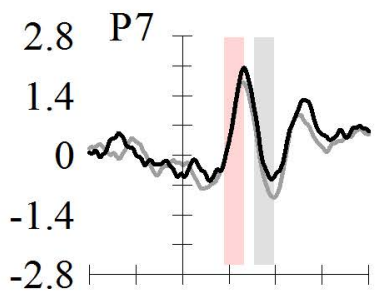

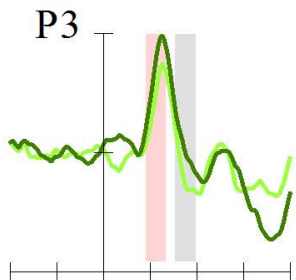
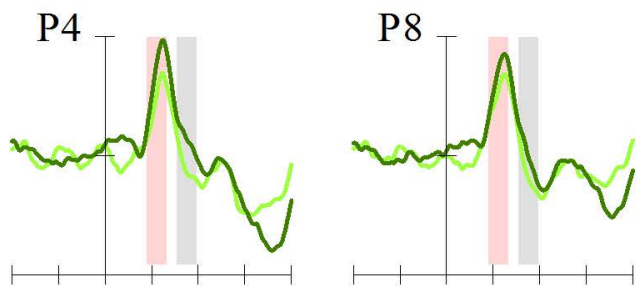

— with Words - with Symbols
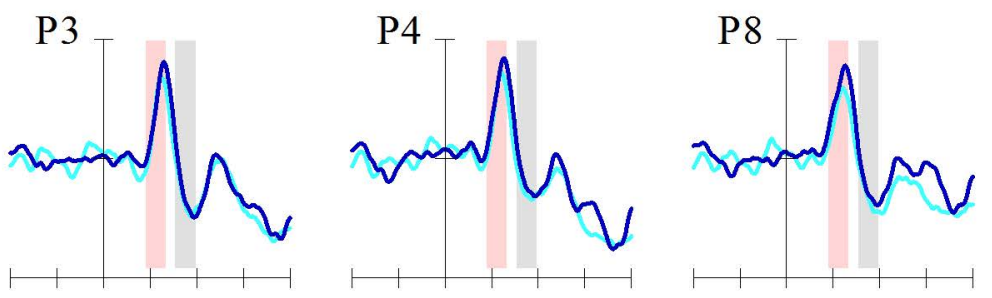

— with Words - with Nonwords

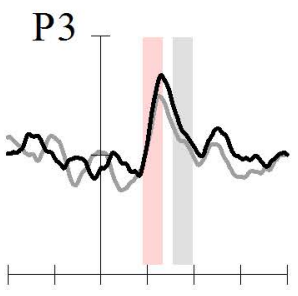

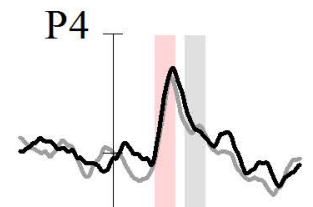

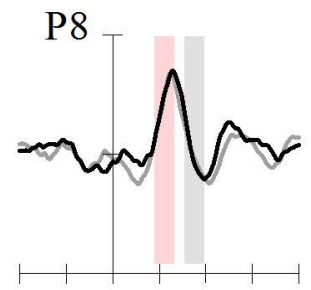


(a) $80-120 \mathrm{~ms}$

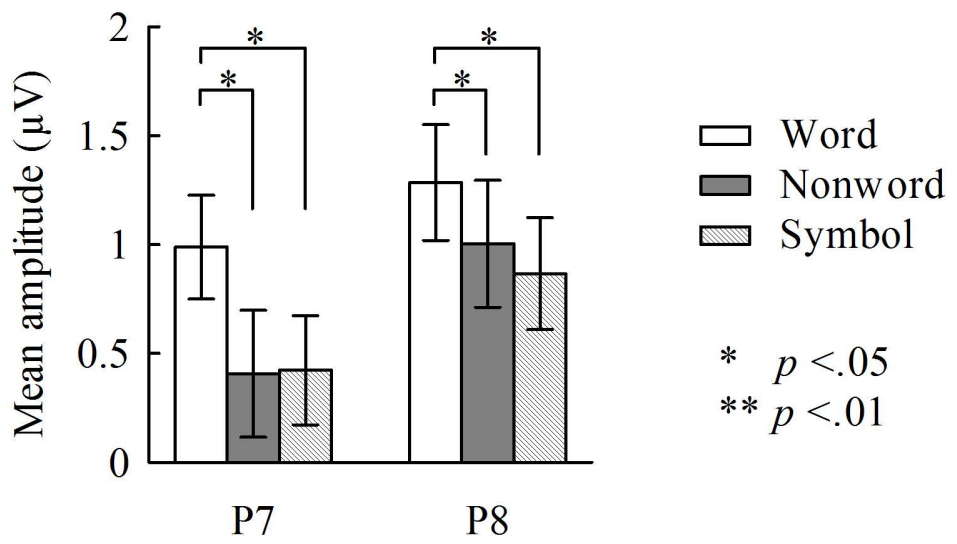

(b) $150-200 \mathrm{~ms}$
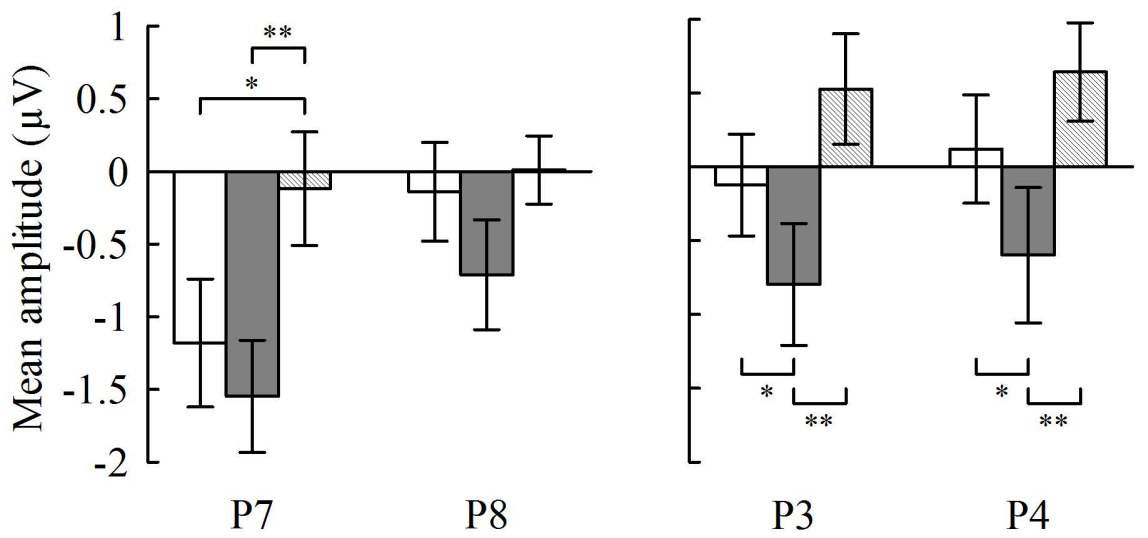